\title{
Telesupervised Remote Surface Water Quality Sensing
}

\author{
Gregg Podnar \\ Robotics Institute \\ Carnegie-Mellon University \\ Pittsburgh PA 15213 USA \\ (412)268-6273 \\ gwp@cs.cmu.edu
}

\author{
John M. Dolan \\ Robotics Institute \\ Carnegie-Mellon University \\ Pittsburgh PA 15213 USA \\ (412)268-7988 \\ jmd@cs.cmu.edu
}

\author{
Kian Hsiang Low \\ Dept. of Computer Science \\ National University of \\ Singapore \\ Republic of Singapore \\ lowkh@comp.nus.edu.sg
}

\author{
Alberto Elfes \\ Jet Propulsion Laboratory \\ NASA \\ Pasadena CA 91109 USA \\ (818)939-6487 \\ Alberto.Elfes@jpl.nasa.gov
}

Abstract - We present a fleet of autonomous Robot Sensor Boats (RSBs) developed for lake and river fresh water quality assessment and controlled by our Multilevel Autonomy Robot Telesupervision Architecture (MARTA).

The RSBs are low cost, highly maneuverable, shallow draft sensor boats, developed as part of the Sensor Web program supported under the Advanced Information Systems Technology program of NASA's Earth Systems Technology Office. They can scan large areas of lakes, and navigate up tributaries to measure water quality near outfalls that larger research vessels cannot reach.

The MARTA telesupervision architecture has been applied to a number of domains from multi-platform autonomous wide area planetary mineral prospecting, to multi-platform ocean monitoring.

The RSBs are a complementary expansion of a fleet of NOAA/NASA-developed extended-deployment surface autonomous vehicles that enable in-situ study of meteorological factors of the ocean/atmosphere interface, and which have been adapted to investigate harmful algal blooms under this program.

The flexibility of the MARTA telesupervision architecture was proven as it supported simultaneous operation of these heterogenous autonomous sensor platforms while geographically widely separated.

Results and analysis are presented of multiple tests carried out over three months using a multi-sensor water sonde to assess water quality in a small recreational lake. Inference Grids were used to produce maps representing temperature, $\mathrm{pH}$, and dissolved oxygen. The tests were performed under various water conditions (clear vs. hair algae-laden) and both before and after heavy rains.

Data from each RSB was relayed to a data server at our institution in Pittsburgh, Pennsylvania, and made available over the World Wide Web where it was acquired by team members at the Jet Propulsion Laboratory of NASA in Pasadena, California who monitored the boats and their sensor readings in real time, as well as using these data to model the water quality by producing Inference Grid-based maps.

\footnotetext{
${ }^{1}$ IEEEAC paper \#1617, Version 1, Updated January 5, 2010

${ }^{2}$ 978-1-4244-3888-4/10/\$25.00 (C2010 IEEE.
}

\section{TABLE OF CONTENTS}

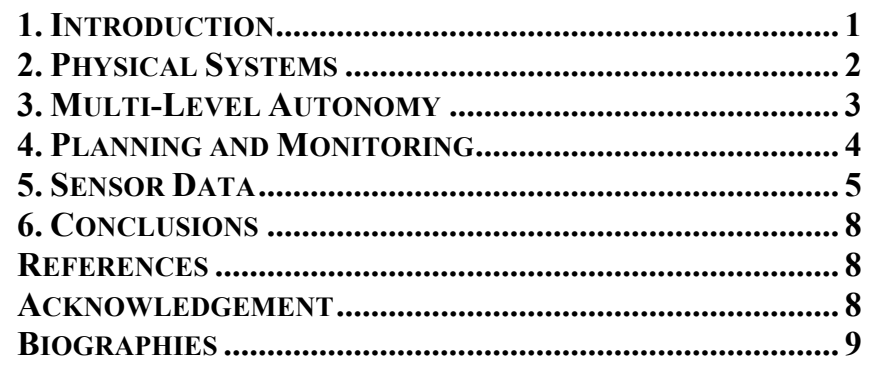

\section{INTRODUCTION}

At least three in every four humans depend on "surface water as its primary source of drinking water." [1] Water resources in a region are critical to economic growth as well as to quality of life. Water quality data give us insight into the suitability of the water for aquatic life and for human use; and help us understand how chemicals move in our environment, particularly contaminants and pollutants whose transport and persistence in the environment are critical to plans for long term remediation.

\section{The Ohio River Basin}

In 2005, the National Research Council completed its study, "Regional Cooperation for Water Quality Improvement in Southwestern Pennsylvania." [2] This report focused on the need for a comprehensive watershed-based approach in the region, and specifically called for increased data collection and modeling of critical water resources. With ten percent of the U.S. population living in the Ohio River basin, any accidental or intentional introduction of contaminants on the river would have widespread impact.

Contamination of Pittsburgh surface waters has been greatly reduced over the last three decades by both a concerted effort to control industrial wastes and the reduction of heavy industry. Nevertheless, incidents of significant accidental and intentional contamination continue. Industrial waste dumping, storage tank ruptures, acid mine drainage, combined sewer overflows, and train derailments (Figure 1) all contribute to crisis situations of critical surface water systems. 


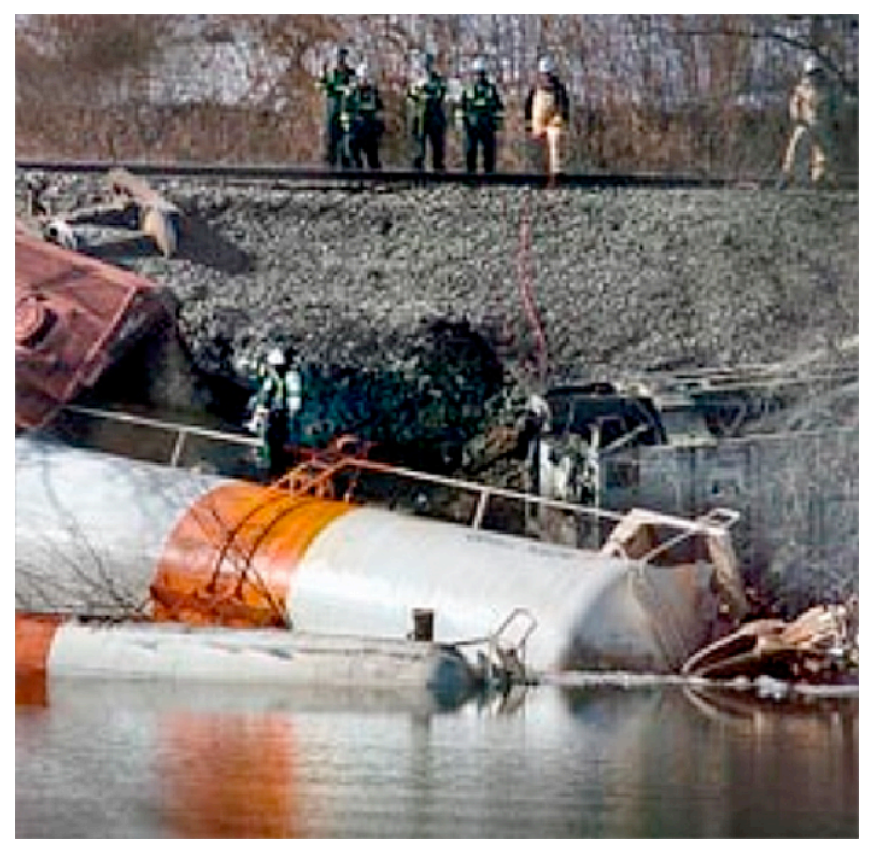

Figure 1. Derailment releases anhydrous hydrogen fluoride into the Allegheny River [3]

\section{Collecting Water Quality Data}

The local collection of water quality data has lagged other data collection activities for several reasons. Water is a widely distributed resource, and the quality and movement of water can be affected by things happening at multiple spatial and temporal scales. Sensors to monitor water are expensive and require routine maintenance and cleaning that is difficult with remote installations. Despite these challenges, sensors and sensor networks for environmental data are expected to revolutionize environmental monitoring, leading to widespread "pulse-taking" of the natural and built environments. [4] Further, linking sensor data with multi-scale, multi-component modeling through cyber-infrastructure is expected to significantly increase our understanding of environmental systems and enhance our ability to make policy decisions. [5]

Collection of water quality data also serves important outreach and educational objectives. Ecology and the environment resonate with the public, especially the young. This has been the basis of many experiential environmental programs designed to expand the interest of children in Earth science and technology.

\section{Mobile Sensor Systems}

Mobile sensor systems for gathering water quality data have many advantages over sensors geographically fixed in surface waters or those fixed in intakes for drinking water processing facilities. Some of these advantages are:

- The ability to monitor at locations inaccessible to fixed sensors (e.g., in navigation lanes).

- Real-time monitoring of water contamination levels by tracking with a volume of water as it flows past water intakes and recreational areas.

- The ability to quickly change monitoring locations. This allows monitoring at many more locations than fixed sensors. Further, it decreases the likelihood that monitoring locations are known to individuals, groups, or corporations who may desire to introduce contaminants.

- The ability for one human to remotely supervise multiple mobile robotic sensor boats. In addition to the efficiency this supports, the human observer is not exposed to the contamination as would be the case when testing water quality or gathering samples from a regular boat.

Fixed sensors will continue to provide necessary data, but their fixed nature can be exploited by individuals, groups, or companies who wish to intentionally introduce contaminants. Mobile sensing boats, whose position is inherently unpredictable, eliminate possible foreknowledge of sensor positions, thus being a significant deterrent.

The research components of this work include the physical systems to monitor surface fresh water for quality and security by extending human capabilities through a fleet of semi-autonomous Robotic Sensor Boats; and a multi-level control architecture that supports inferenced temporal scientific analysis of the water quality data collected in situ.

\section{Physical Systems}

To monitor surface fresh water for quality requires physical systems which include: mobile, in situ data collection; wireless communications for monitoring, control, and data collection; and a repository for archiving the data and sharing it widely with other researchers.

\section{Robot Sensor Boats}

For the mobile deployment of water quality sensors, a fleet of small relatively inexpensive Robotic Sensor Boats (RSB) (Figure 2) has been developed.

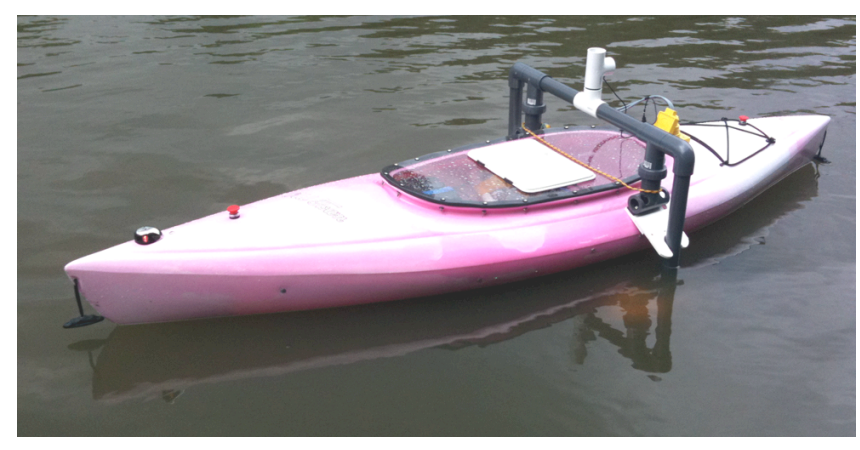

Figure 2. Robot Sensor Boat (RSB-2)

Performance requirements include the ability to navigate upstream faster than the velocities of the local rivers which are usually less than one mile per hour; an operational time of at least four hours; and communications for both telemetry and water quality sensor data. 
To minimize costs and development time, we used a variety of commercially-available components including the hull, propulsion system, and communications. Customization was kept to a minimum with the primary focus being kept on the sensing and navigation requirements.

Relatively inexpensive small recreational kayaks form the basis for each boat. These are single-piece rotary-molded ultra-high molecular weight polyethylene hulls.

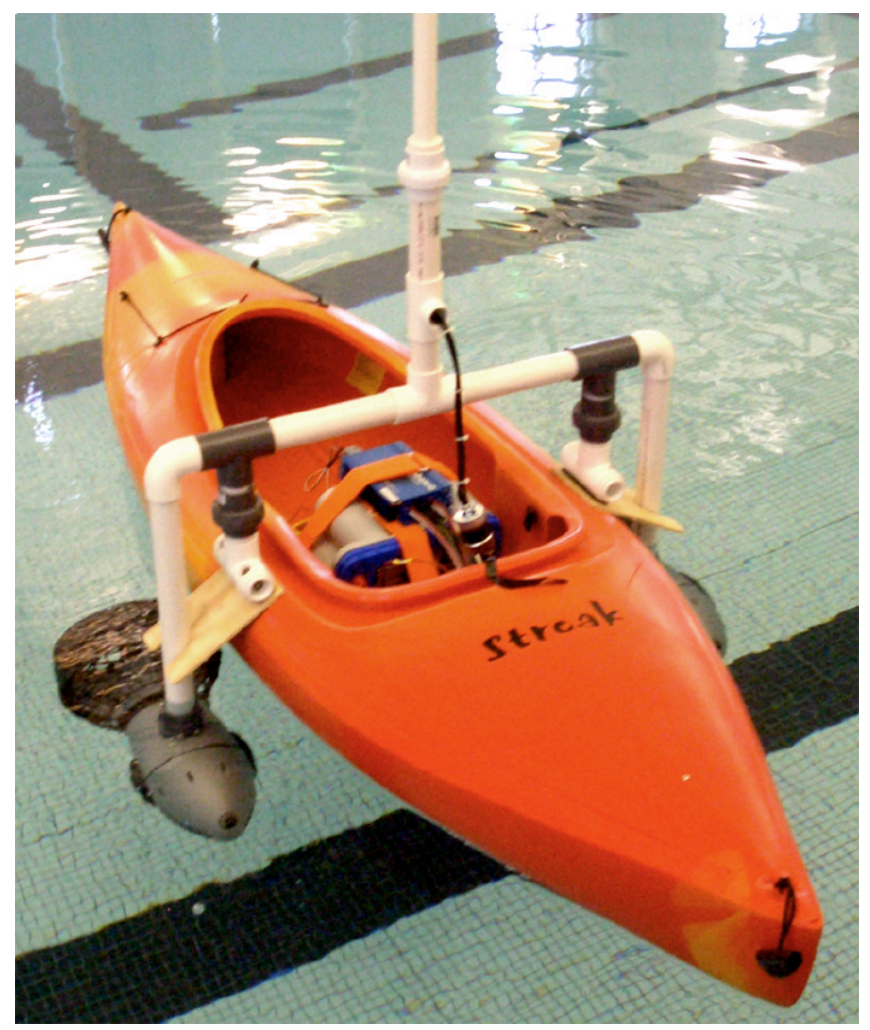

Figure 3. Initial pool tests of RSB-1 showing dual thrusters adapted from Dive Propulsion Vehicles

Each RSB is fitted with ducted thrusters based on personal Dive Propulsion Vehicles (Figure 3) mounted to each side with screens to exclude foreign materials that might clog the propellers. The rudderless dual-ducted design allows simple differential steering and provides adequate speed (3-4 mph) when deploying each boat to its sampling area. They are also inherently safe for curious swimmers, and for researchers when launching or retrieving the RSBs. Nevertheless, emergency stops, and override manual radio remote control is also provided.

Deep-cycle marine batteries provide adequate power to operate for over six hours. Total weight was kept within $100 \mathrm{lbs}$. (45 kg.) to allow the boat to be loaded, carried, and launched by two people. A deck with waterproof hatch (Figure 2) seals the opening normally used by the human paddler, keeping the computer and control electronics dry.

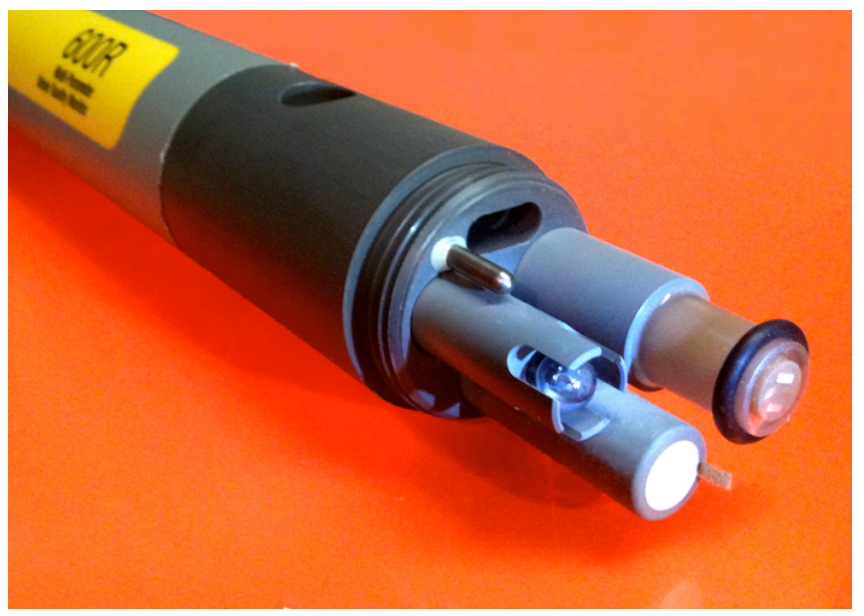

Figure 4. YSI-600R Water Sonde.

\section{Science and Navigation Sensors}

For science data measurements, a commonly-employed multi-sensor water quality sonde (Figure 4) provides data on: temperature, conductivity, dissolved oxygen, and $\mathrm{pH} / \mathrm{ORP}$. For navigation, a magnetic compass and a GPS are supported. All the sensors are interfaced to the on-board computer.

\section{Communications}

For control, telemetry, and science data, each RSB has an on on-board computer for autonomous operation, and communicates via a cellular modem the lab.

\section{Data Archiving and Sharing}

The data collected are archived on a data server at our institution. This may be accessed by scientists immediately as the test are being conducted, and both these and historical data are made accessible to other scientists via the World Wide Web.

\section{Multi-Level Autonomy}

Our Multilevel Autonomy Robot Telesupervision Architecture (MARTA) provides an integrated approach to multi-robot coordination and multi-level robot-human autonomy. (Figure 6) It allows multiple robotic sensing assets (both mobile and fixed) to function in a cooperative fashion, and the operating mode of different robots to vary from full autonomy to teleoperated control.

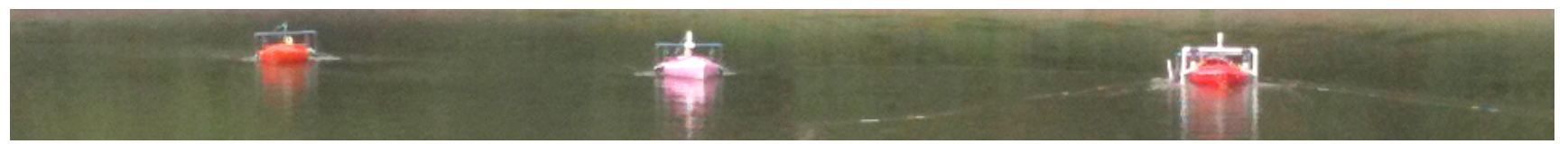

Figure 5. RSB-3, RSB-2, and RSB-1 operating simultaneously. 
High-level planning and monitoring allow a human telesupervisor to assign to a fleet of robotic assets high-level goals, such as specifying an area of water or section of river to investigate, which are then automatically subdivided and operational commands sent to each robot by the Robot Team Coordinator. As the robots execute these plans their operation is monitored both by the Robot Team Coordinator module and by the human telesupervisor. Adaptive replanning of the robot assignments is based on sensor inputs (dynamic sensing) and coordination between multiple assets, thereby increasing data-gathering effectiveness while reducing the human effort required for tasking, control, and monitoring of the vehicles.

Multi-level autonomy includes low-level autonomy on each independently-operating robot; autonomous monitoring of the fleet; adaptive replanning; and when necessary,
A planning interface that provides for automatic generation of area coverage rectilinear waypoint trajectories that define a raster scan is shown in Figure 7. Each waypoint is defined with an "achievement circle" that allows for less-than-exact waypoint achievement. The apparent distortion of the raster pattern as depicted in the path being specified reflects adjustments to the positions of the waypoints which take into account the size of the achievement circle, the accuracy of the GPS, and the capability of the RSBs to make very tight turns.

The resulting real-world trajectory of the RSB then much more approaches a neat rectilinear raster pattern.

For multi-platform monitoring of telemetry, our NASA partners at JPL developed an interface that allows flexibility in defining robot assets, and monitoring their operation.

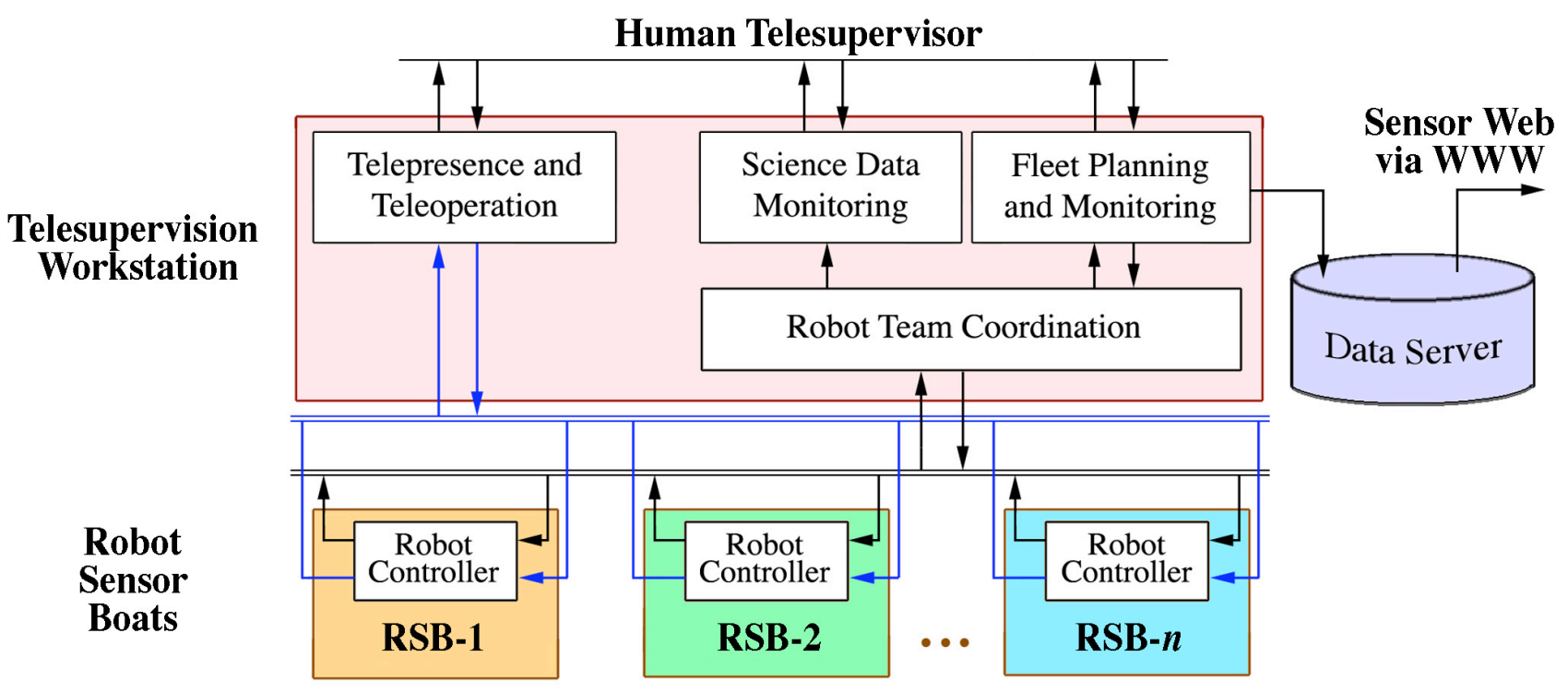

Figure 6. Multilevel Autonomy Robot Telesupervision Architecture (MARTA)

intervention by the human telesupervisor either with manual replanning, or by taking direct control of a robot via teleoperation.

Algorithms for science analysis of the acquired data can perform an initial assessment of the presence of specific science signatures of immediate interest both onboard each robot, and at the telesupervisor's workstation. Web-based communications support both control and communications over long distances of the robotic fleet, and the sharing of currently-sensed and historical data with remote experts.

\section{Planning and Monitoring}

The human telesupervisor controls and monitors the robotics assets through a variety of interfaces as diagrammed in Figure 7.

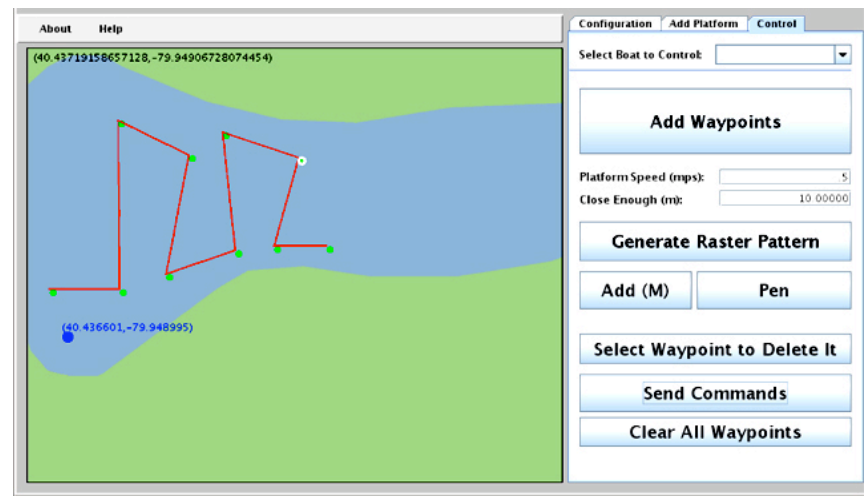

Figure 7. RSB waypoint planning interface.

Figure 8 shows monitoring of a multi-platform test of two ocean-going NASA/NOAA-sponsored sensor platforms in the Chincoteague Bay, operating simultaneously with two of our RSBs in Pittsburgh. 


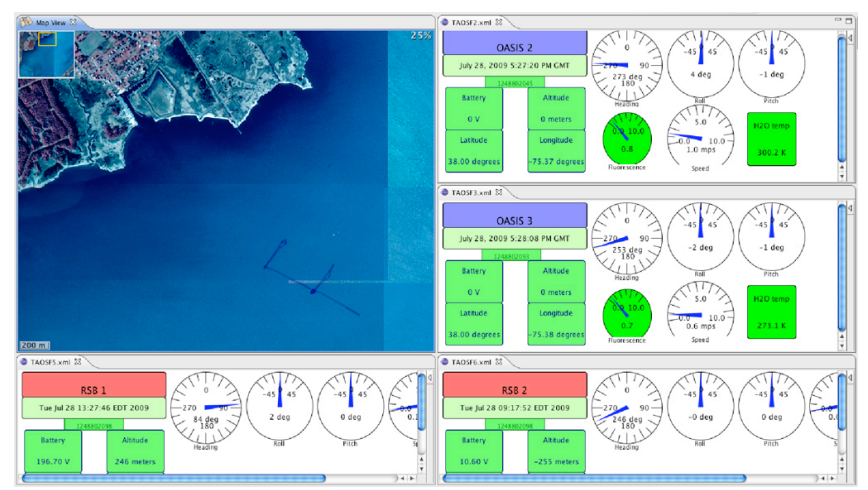

Figure 8. Multi-platform monitoring "dashboards".



Figure 9. Initial navigiation test of RSB-1.

We also ported a platform navigation control simulation model we had originally implemented in Matlab giving the transfer function between rudder-angle command and velocity direction into the $\mathrm{C}$ programming language in order to be able to integrate it into the navigation control for the RSBs. The magnetic compass is necessary to augment the latitude and longitude data from the GPS to provide the navigation algorithm instantaneous heading information even when the boat is not moving.

\section{Initial Navigation Tests}

We conducted the first outdoor in-water test of the RSB in Panther Hollow Lake, a man-made lake in Schenley Park, which adjoins Carnegie Mellon University (CMU). Figure 9 shows RSB-1 navigating on the surface of Panther Hollow Lake.

\section{Multiple Water Quality Data Gathering Tests}

During June, July, and August 2009, eight tests were conducted on Panther Hollow Lake. The tests were performed under various weather and water conditions. The quantity of "hair algae" supported by the lake can be seen in Figures 10 and 11. This developed during a few weeks after our initial tests. After one very heavy rain, the lake began to clear significantly.



Figure 11. RSB-1 and "hair algae".

\section{Sensor Data}

Figure 12 is an aerial image of Panther Hollow Lake, and the rectangle shown with a dashed red line is the area in which the data shown in Figure 13 were taken. The Lake's average depth was originally six feet, but is now closer to three feet after years of erosion-caused soil deposits. The inlet is at the East end of the lake (to the right of Figure 12),

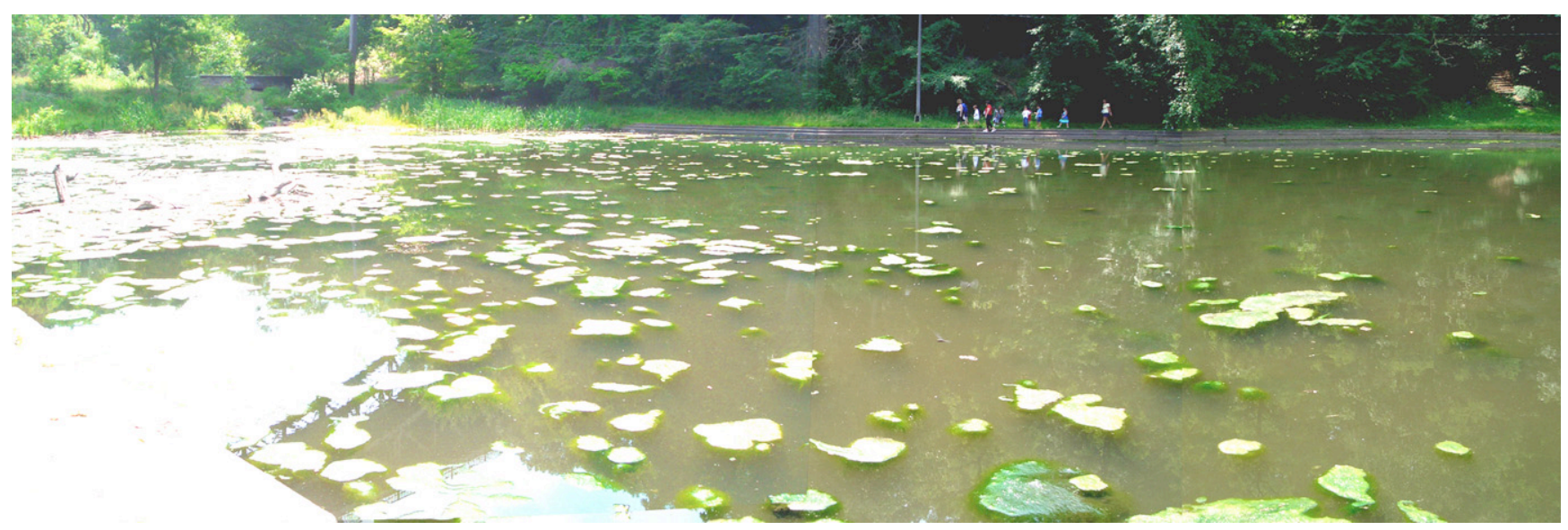

Figure 10. Panorama of nutrient-rich Panther Hollow Lake showing the quantity of "hair algae" in July. 
which is now very shallow. The shadow on the right of Figure 12 is caused by a bridge 120 feet above the surface of the lake.

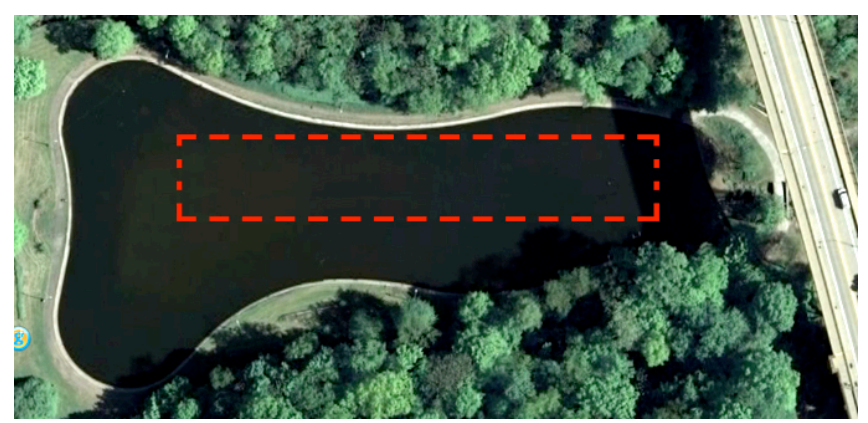

Figure 12. Panther Hollow Lake showing the area surveyed by the RSB.
Specifically, the temperatures were higher to the left of the image and lower on the right, where the bridge casts a shadow. The high dissolved oxygen readings on the right may be related to the presence at that end of the lake of a layer of algae.

\section{Multiple Multi-Sensor Maps of Panther Hollow Lake}

Additional scans shown in Figures 14 and 15 were made on June 10 from 13:39-15:00 EST, and on June 16, 2009 from 12:59-13:39 EST, and represent a shorter and wider testing area which was chosen to avoid submerged branches and an abandoned shopping cart that were just under the surface.

The inference maps on 10 June were constructed using a dataset of 359 synchronized GPS and science samples combining two test runs, and the inference maps on 16 June were constructed using a dataset of 200 synchronized GPS

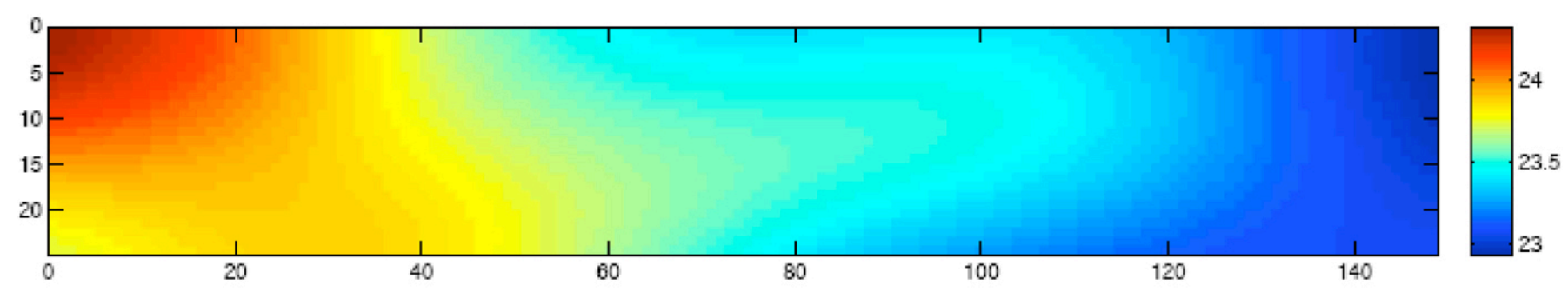

Figure 13a. Temperature data, degrees Celsius.

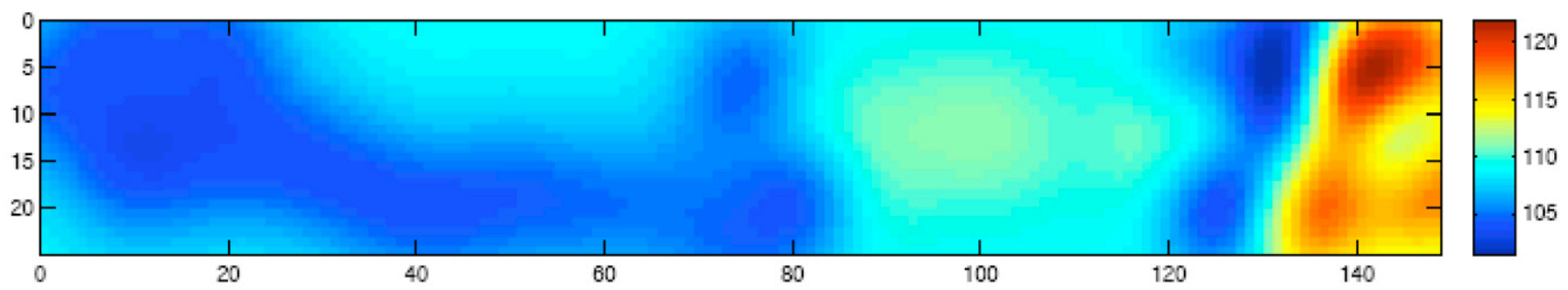

Figure 13b. Dissolved oxygen data, mg/L.



Figure 13c. pH data

Figure 13. Gaussian process-based inferences of the data. Values shown in color scale to right of each plot.

\section{Initial Mapping of Panther Hollow Lake}

The initial mapping of the test area of Panther Hollow Lake on May 29, 2009 gave the results shown in Figure 13. The inferred fields for the temperature, dissolved oxygen, and $\mathrm{pH}$ are reconstructed using a dataset of 380 synchronized GPS and science data of the first test run during the period of 16:30:41 to $16: 56: 21$ EST. The data are smoothly varying and the temperature and dissolved oxygen make sense given what we can observe independently about the lake. and science samples.

As compared to the temperature field on 29 May (Figure 13a), the 10 June temperature field (Figure 14a) is warmer, which is expected since it is early afternoon. Similar to the temperature field on 29 May, the west end of the lake is warmer. 
As compared to the dissolved oxygen field on 29 May (Figure 13b), the 10 June dissolved oxygen field (Figure 14b) has much higher levels of dissolved oxygen, which can be explained by the bountiful plant life (Figure 10).

As compared to the $\mathrm{pH}$ field on 29 May (Figure 13c), the 10 June $\mathrm{pH}$ field (Figure 14c) is less acidic. Different from the $\mathrm{pH}$ field on 29 May, it is less acidic on the west end of the lake.

As compared to the temperature fields on 29 May and 10 June, the 16 June temperature field (Figure 15a) is the warmest.

As compared to the dissolved oxygen field on 10 June, the 16 June dissolved oxygen field (Figure 15b) has lower levels of dissolved oxygen. But, it has higher levels of dissolved oxygen than the field on 29 May.

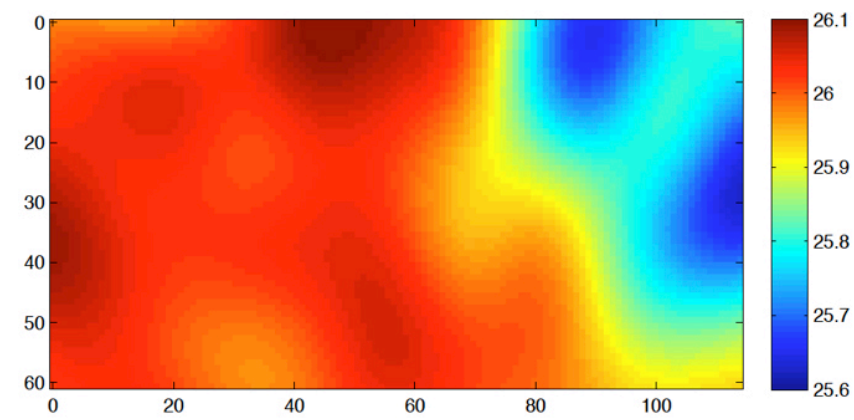

Figure 14a. June 10, 2009 Temperatures.

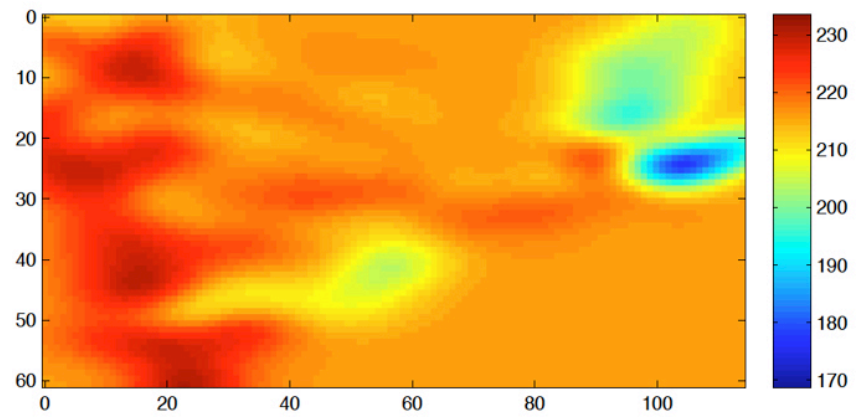

Figure 14b. June 10, 2009 Dissolved Oxygen.

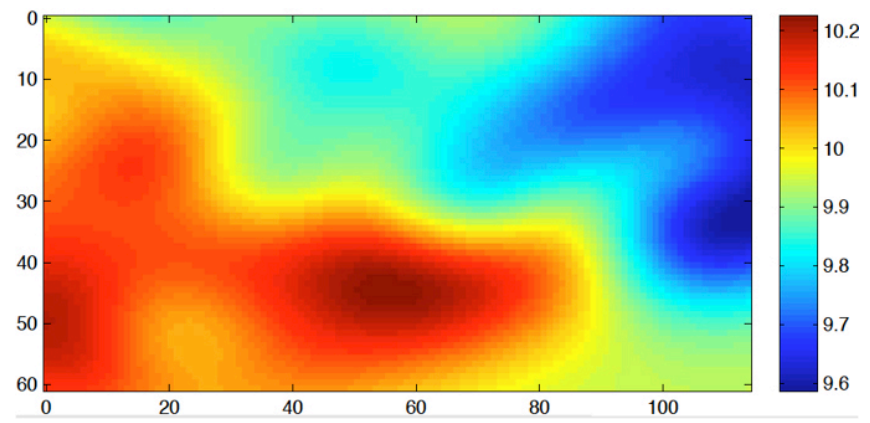

Figure 14c. June 10, 2009 pH.
As compared to the $\mathrm{pH}$ field on 10 June, the 16 June $\mathrm{pH}$ field (Figure 15c) is more acidic. But, it is less acidic than the field on 29 May.

\section{Data Analysis}

The qualitative assessment of these data provide an indication of the rapidly-changing conditions in this shallow lake.

The quantitative analysis of these data is being carried out by Water QUESt, Water Quality in Urban Environment Systems, a project led by Professor Jeanne Van Briesen in Carnegie Mellon University's Civil Engineering department that monitors water quality in Panther Hollow Lake in connection with a restoration of the lake planned by the Pittsburgh Parks Conservancy.

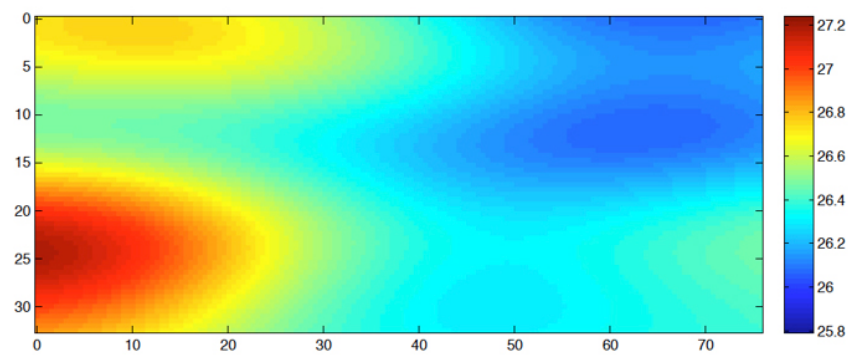

Figure 15a. June 16, 2009 Temperature.



Figure 15b. June 16, 2009 Dissolved Oxygen.



Figure 15c. June 16, 2009 pH. 


\section{CONCLUSIONS}

Our primary goals included proving the utility of our telesupervision architecture for surface water quality sensing.

To ensure the practical application, we not only integrated the physical systems of the RSBs with our telesupervision architecture and deployed them for multiple tests into the environment of the lake (with all the vagaries of field deployments including the concomitant wireless remote networking issues), but by also holding the higher goal of conducting an in situ sensing task; that of collecting multisensor water quality data; we prove the entire system to be viable for real-world remote sensing.

The physical systems of the boats, sensors, onboard control and monitoring, wireless communication, telesupervision workstation, and data server were well proven in multiple tests over an entire season.

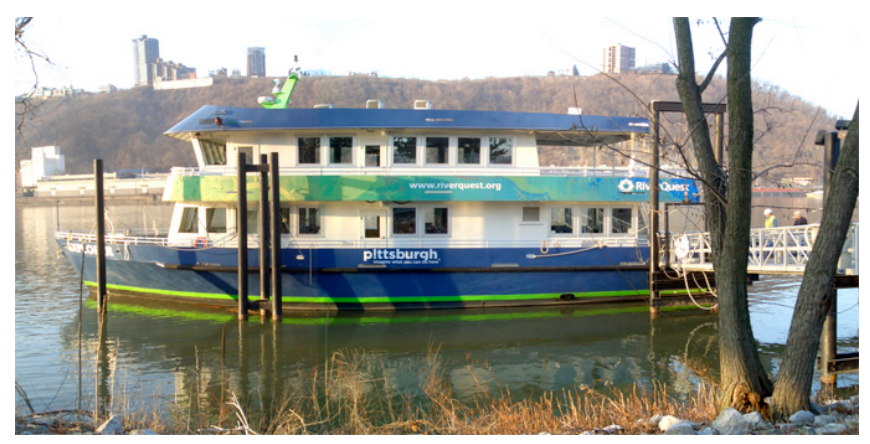

Figure16. Pittsburgh RiverQuest “Explorer".

\section{Future Opportunities}

There are a number of promising opportunities for future application of this instantiation of our Multilevel Autonomy Robot Telesupervision Architecture.

We have an ideal opportunity to synergistically accomplish educational and operational goals through a collaborative relationship with RiverQuest, a Pittsburgh-based non-profit that operates experiential education programs on research boats in Pittsburgh's rivers. By allowing students to control and monitor the RSBs from RiverQuest's floating research classroom, "Explorer" (Figure 16), through the Telesupervision Workstation, we will simultaneously achieve a number of goals:

- Give hands-on experience to students and teachers at all levels operating cutting-edge telesupervised robotic technology while doing real science, and collecting valuable data.

- Collect data regularly at many varied locations over a large area.

- Allow for a rapid deployment in a crisis situation while the RSB fleet is kept ready for the next class.
- Conduct long-term ongoing data collection and analysis, and widely share the data after the initial research effort has been completed. This benefits both those conducting the experiments, and those scientists accessing the stored data over time.

This experiential water quality-based program on the three rivers of the Pittsburgh region, will give students and teachers a real experience of doing science from the remote data gathering, the data analysis, and the wide sharing of data with other researchers. This puts the students at the center of this wide variety of computing-based tools and engages them in the cutting-edge questions that result from sensor deployment and advancing information technology.

\section{REFERENCES}

[1] National Research Council. "Earth Science and Applications from Space: National Imperatives for the Next Decade and Beyond", 2007.

[2] National Research Council, "Regional Cooperation for Water Quality Improvement in Southwestern PA.", National Academies Press 2005.

[3] Pittsburgh Post-Gazette, "200 evacuated after derailment sends tanker cars into Allegheny River", February 01, 2005, Mike Bucsko, (photo Darrell Sapp).

[4] National Science Board, "Environmental Engineering and Science for the 21st Century: Role of the National Science Foundation", NSB00-22. Washington DC, 2000.

[5] National Science Foundation, Cyberinfrastructure Council 2005.

\section{ACKNOWLEDGEMENT}

This work was supported by NASA award NNX06AF27G, "Telesupervised Adaptive Ocean Sensor Fleet", granted under the Advanced Information Systems Technology program of NASA's Earth Systems Technology Office (ESTO).

We also wish to acknowledge the many students and assistants working on MARTA and the RSBs at CarnegieMellon University: David Asikin, Masters Student; Christopher Baker, PhD Student; Jeffrey J. Baker, Research Programmer; Alex Billing, Visiting Summer Intern; Imen Borgi, Visiting Scholar; Matthew Felser, Summer Research Programmer, Alan D. Guisewite, Webmaster/Special Project Assistant; Vinay Gunasekaran, Student Summer Researcher; Ellie Lin Ratliff, PhD Student; David Schlesinger, Summer Research Programmer; and Stephen B. Stancliff, PhD Student. 


\section{BIOGRAPHIES}



Gregg Podnar is a Program Manager of Carnegie-Mellon University's Robotics Institute, and has three decades of extensive research and development experience building many task-specific mobile robots; manipulators; stereoscopic telepresence systems; and surgical instruments. He holds U.S. and international patents; is the author of over 30 papers on robotics, stereoscopic imaging, and engineering design; and has taught computer science in China. He also leads a program for electric passenger automobiles focused on efficient energy storage and management combining moderate-rate batteries and supercapacitors.



John M. Dolan is a research faculty member of Carnegie Mellon University's Robotics Institute with interests in multirobot systems, sensor-based control, autonomous driving, and robot reliability. He was the behaviors team lead for CMU's winning entry in the 2007 DARPA Urban Challenge, and serves on the program committee of leading robotics conferences, including AAMAS and RSS.

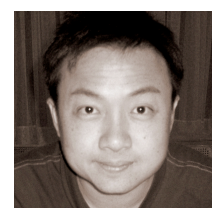

Kian Hsiang Low obtained a B.Sc. (Hons.) and a M.Sc. in Computer Science from National University of Singapore, Singapore, in 2001 and 2002, respectively, and the Ph.D. degree in Electrical and Computer Engineering from Carnegie Mellon University, Pittsburgh, PA, in 2009. His research interests include adaptive sampling, active learning, statistical machine learning, and multi-agent and multi-robot coordination, planning, and learning. He is the recipient of Andrew $P$. Sage Best Transactions Paper Award for the best paper published in all 3 of the IEEE Transactions on Systems, Man, and Cybernetics - Parts A, B, and C in 2006. He has served in the program committees of AAAI 2010 and ICAPS 2010.

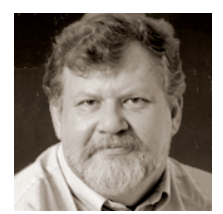

Alberto Elfes obtained a Ph.D. in Electrical and Computer Engineering from CarnegieMellon University in 1989. He was a research scientist at the CMU Robotics Institute, and at the IBM T. J. Watson Research Center. From 1994 to 2000, Dr. Elfes was the lead for a United Nations Development Program (UNDP) project in strategic information technologies, and director of the Automation Institute, Brazil. He received the Mercator Professorship Award of the German Research Foundation (DFG) in 2000. Dr. Elfes is presently a Principal Member of Technical Staff at the Jet Propulsion Laboratory, leading projects in autonomous aerial and aquatic robots, as well as in lunar mission planning and assessment. 
